Altogether, thirty-three new monosubstituted pteridines have been prepared. The accompanying table provides an index to the synthesis and properties of these substances, and also to the two examples discovered elsewhere. The gaps in the table, occurring in the 6-series, are attributable to the instability of intermediates.

The most stable pteridines are those with electronreleasing substituents (for example, - $\mathrm{OH}$ ). Conversely, pteridines with substituents more electronattracting than chlorine are expected to be highly unstable, and no examples are known having this type of substituent alone.

Department of Medical Chemistry*,

Adrien Albert

Australian National University.

April 5.

- Present address : 183 Euston Road, London, N.W.1.

\section{Early Arrivals in Seismic Prospecting}

THE conventional seismic prospecting record, showing vibrations propagated from a dynamite explosion, generally fails to yield any useful information during the first one- or two-tenths of a second after the initial onset. As a result, the study of propagation in shallow strata is for the most part limited to what can be learned from the travel-times of first arrivals. This limitation has affected the application of the seismic method to shallow prospecting problems. It also tends to hamper the experimental study of seismic propagation, since the effects of the shallower strata are often difficult to observe.

An electromechanical seismic source ${ }^{1}$ has been developed for experimental purposes to allow more control over the generated impulse than is possible with the usual explosive source. This controlled

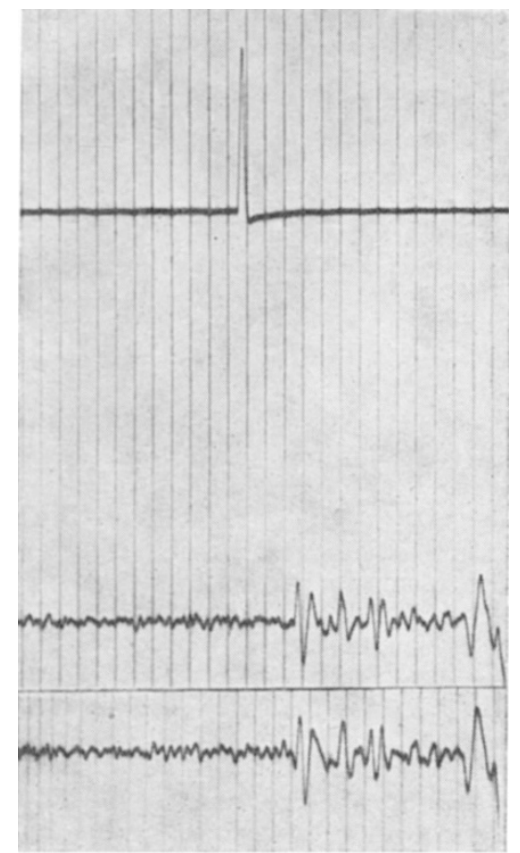

Fig. 1. Seismic record obtained with an electromechanical source, showing distinct early arrivals. A single geophone channel was used, but two records obtained in the same conditions are here juxtaposed to show the reproducibility. The top trace shows the voltage nulse applied to the source. Timing lines are at intervals
of $10 \mathrm{~m}$.sec. The distance from source to geophone was $125 \mathrm{ft}$. source has proved useful in several series of experiments in underground tunnels 1,2 , and has recently been tested for the first time at the surface. In these results the confusion normally found in the early part of a seismic record is absent.

Fig. 1 shows an example of the recorded geophone signal, containing several distinct early arrivals. Second and third arrivals may readily be distinguished within $50 \mathrm{~m} . \mathrm{sec}$. of the first, and a large fourth arrival is seen some $40 \mathrm{~m}$.sec. later. Such a succession of arrivals is more reminiscent of the kind of record obtained in laboratory experiments with ultrasonic pulses. Near-surface geological conditions at the site of the observations were not unusual : sediments several hundred feet thick, having seismic velocities in the range $6,000-7,000 \mathrm{ft}$./sec., were covered by some $15 \mathrm{ft}$. of unconsolidated material, within which lay the water-table.

If the early arrivals in a seismic record can be resolved, the possibility of a shallow-reflexion technique arises. Initial onsets are normally due to direct waves or shallow refractions, which precede even the shallowest reflexions, so that in practice the standard technique seldom reveals reflecting boundaries shallower than about $400 \mathrm{ft}$. For deeper prospecting, on the other hand, the method of reflexions is steadily superseding the older refraction method.

Early arrivals have been sought in work with other unconventional sources, such as hammer-blows ${ }^{3}$ and very small explosive charges, but with little success. Although the present electromechenical source suffers from low power and large bulk, it seems to offer a distinct advantage over other known sources for shallow seismic work. A detailed account of the experiments and an interpretation of the results will be published elsewhere.

\section{F. F. Evison}

Geophysics Division,

Department of Scientific and Industrial Research, Wellington, New Zealand.

Feb. 9.

'Evison, T. F., N.Z. J. Sci. Tech., 35, 4 (1953),

2 Evison, F. F., Mon. Not. Roy. Astro. Soc., Geophys. Supp., 6, 209 (1951).

${ }^{3}$ Gough, D. I., Geophysics, 17, 311 (1952).

\section{Photomicrography with a Kellner Eyepiece}

BELow the lens system of a Kellner eyepiece there is a stop for supporting micrometers in the image plane, and if a small photographic plate is supported on this stop it will receive the primary image when the microscope has been correctly focused. To ensure this, a cover-slip with fine ink-markings on its undersurface is placed on the stop and adjustments made until object and markings are in focus. The lens system and cover-slip are then removed from the eyepiece and the microscope lamp switched off. Under appropriate dark-room conditions the plate is inserted emulsion downwards and protected by a light-proof cap while the exposure is being made.

The method has been found useful in preparing photomierographs of mineral grains (Fig. 1). Using 15-mm. squares cut from lantern plates and an ' $M Q$ ' or a caustic hydroquinone developer, sharp contrasty negatives have been obtained, sufficiently fine-grained to be enlarged fifteen times or more. For some subjects 'contact' (chloride) lantern plate was used, and with a 100-watt pearl lamp exposures were not unduly long if the magnification was small, 